\title{
Sosyal Bilgiler Öğretmenlerinin Tarihi Kültürel Miras Eğitimine ilişskin Görüşleri (Denizli Şehri Örneği) ${ }^{1}$
}

\section{Social Studies Teachers' Views on Historical Cultural Heritage Education (The Case of Denizli)}

\section{Seher Azrak², Elvan Yalçınkaya}

Anahtar Kelimeler
sosyal bilgiler
kültür
tarihi kültürel miras
tarihi kültürel miras
eğitimi

\section{Keywords}

social studies

culture

historical cultural

heritage

historical cultural

heritage education

Başvuru Tarihi/Received

18.07.2019

Kabul Tarihi /Accepted

26.10.2019
Öz

Bu araştırmada, Denizli ilindeki sosyal bilgiler öğretmenlerinin tarihi kültürel miras eğitimi ile ilgili görüşleri ortaya konulmaya çalışılmıştır. Araştırmada olgu bilim deseni kullanılmış, 20 sosyal bilgiler öğretmeninin görüşleri alınmıştır. Veri toplama aracı olarak görüşme formu kullanılmıştır. Ortaya çıkan verilerin analizinde içerik analizi yöntemi kullanılmıştır. Araştırma sonucunda, öğretmenlerin tarihi kültürel miras eğitimine ilgili oldukları görülmüştür. Tarihi kültürel miras eğitiminde görsel materyal eksikliği en çok karşılaşılan sorun olmuş ve bu konu için de en çok tercih edilen teknik gezi gözlem olmuştur. Öğretmeler tarafından tarihi kültürel miras eğitiminin Türkçe dersinde de verilmesinin uygun olduğu belirtilmiştir. Ayrıca öğretmenlerin Denizli'deki tarihi kültürel miras ögelerine karşı ilgisiz olmadıkları görülmüştür.

\section{Abstract}

In this research, the views of social studies teachers about historical cultural heritage education in Denizli province were tried to be put forward. Phenomenology pattern was used in the study. In the study, the opinions of 20 social studies teachers were taken. Interview form was used as data collection tool. Content analysis method was used in the analysis of the resulting data. As a result of the research, it is seen that teachers are interested in historical cultural heritage education. The lack of visual material in the education of historical cultural heritage was the most encountered problem and the most preferred technique for this subject was trip-observation. It is also indicated that historical cultural heritage education should be given in Turkish course. Moreover, it was observed that the teachers were not indifferent to the historical cultural heritage elements in Denizli.

\footnotetext{
${ }^{1}$ Bu çalışma, ikinci yazarın danışmanlığındaki birinci yazarın yüksek lisans tezinden üretilmiştir.

${ }^{2}$ Anadolu Üniversitesi, Eğitimi Bilimleri Enstitüsü, Sosyal Bilgiler Eğitimi, Eskişehir, TÜRKiYE; https://orcid.org/0000-0002-0629-4009

${ }^{3}$ Erciyes Üniversitesi, Eğitim Fakültesi, Türkçe ve Sosyal Bilimler Eğitimi, Sosyal Bilgiler Öğretmenliği programı, Kayseri, TÜRKiYE; https://orcid.org/0000-00031838-0411
} 


\section{Extended Abstract}

\section{Introduction}

Purpose and Significance: The course that will offer the best historical cultural heritage education and inform the students is the social studies course (Özbaş, 2012). Therefore, the opinions of the social studies teachers about the historical cultural heritage elements in the application, what is the relationship between the social studies course and the historical cultural heritage education, whether the historical cultural heritage education is given enough place in the social studies course, what methods and techniques can be used when the historical cultural heritage education is given and their views on what are the problems encountered while teaching historical cultural heritage. Therefore, as a result of the findings of this research, it is aimed to gain a new perspective on historical cultural heritage education. in the light of the findings of this study, various suggestions will be made and the results will be discussed. The social studies teachers of these results, it is thought that it will contribute to teacher candidates, program developers and people or organizations who conduct research on social studies education.

\section{Method}

This research was designed in accordance with the qualitative research approach. The aim of qualitative research is; in-depth description, interpretation, understanding the perspective of the individual. One of the qualitative research methods is phenomenological study (Fraenkel and Wallen, 2006'dan aktaran Sözen, 2013). Phenomenology is used in cases we are aware of but we do not have in-depth and detailed understanding of (phenomenology) (Büyüköztürk, Çakmak, Akgün, Karadeniz and Demirel, 2011, s. 19).

\section{Result and Discussion}

In this study, opinions of social studies teachers about historical cultural heritage education were taken. Historical cultural heritage elements are proof for a society that society exists. In order to preserve and maintain historical cultural heritage elements, first of all it is necessary to know what they are and what they cover. For this reason, social studies teachers were asked what the elements of historical cultural heritage cover. Most of the teachers stated that the first element that comes to mind when historical cultural heritage is mentioned is the historical works that shed light on the past. This was followed by tradition and national values. Ünlü (2012)'s survey of primary school students' cultural perceptions were examined. As a result, he stated that the students had different definitions of culture by linking the culture with the past. In addition, it was concluded that we have traditions, customs, oral works, written works, weddings, sports, architectural works, folk dances and many other elements under these themes. Deveci (2009) examined the cultural portfolios prepared by prospective social studies teachers. He tried to reveal the relationship between social studies and culture. As a result of the research, while the teacher candidates explained their own culture, besides the various material and spiritual cultural elements such as weddings, livelihoods, folk dances, folk music and bards and accents, the most common cultural element was the food. The reason for the selection of social studies teachers as a sample group in the field of historical cultural heritage education is that this issue is included in the social studies program as a separate learning area and has many direct and indirect connections with the social studies course. For this reason, the relationship between historical cultural heritage education and social studies education was tried to be revealed by using the opinions of social studies teachers. There are some studies showing that social studies course and historical cultural heritage education course are related. Deveci (2009)'s study reinforces the results obtained from the views of social studies teachers. In the research, all of the pre-service teachers showed that social studies is a human science and the interdisciplinary approach is the reason of the close relationship between culture and social studies. In addition to this, it is stated that the individual learns himself / herself, his / her close environment and other societies with the social studies course in social studies course and therefore cultural education is done in social studies course. Most of the teachers stated that historical cultural heritage education was not included in the social studies program adequately. One of the problems that teachers complained about was the prohibition of proposing extra help books to access information on the subject. Contrary to these views, some of the researches showed that these issues were adequately included in the social studies program. For example, Cengelci (2012) researched the place of intangible cultural heritage in social studies curriculum and observed that intangible cultural heritage elements were included in 7th grade social studies curriculum. In addition to this, it was stated that the examples of acquisition and activity were mostly in the field of culture and heritage learning. Bıyıklı (2010) conducted a research on how cultural heritage is presented in social studies textbooks and how cultural heritage elements are presented. In this research, it is stated that cultural heritage elements have been given importance since the past and therefore visuals about cultural heritage have been included in social studies textbooks from past to present. Leo and Çulha (2008) according to the made clear in the research they do on the 4th and 6th grade students in Turkey research, development of teaching programs in cultural heritage education was concluded to be successful in developing national identity. Some methods should be supported with techniques in order to make the education of historical cultural heritage arouse curiosity and persistence. As a result of this research, these methods and techniques were analyzed in-class and out-of-class. According to the research, most of the teachers preferred observation technique. The research of Dönmez and Yeşilbursa (2014) on this subject supports this. In the study, sixth grade students were given a cultural heritage education consisting of activities related to concrete cultural heritage elements within the scope of social studies course. As a result of this research, it has been effective on students' positive attitude towards concrete cultural heritage. According to some, if there is not a suitable environment and opportunity for sightseeing observation technique, it is stated that teaching with drama and virtual museum should be done. In the same way, there are teachers who stated that it would be possible to see the works belonging to those periods by visiting the museum and that these works could be introduced by making activities in museums. In this study of Ulusoy (2009) on the evaluation of the views of 4th and 5th grade primary school students about the process of learning culture and heritage, it was stated that activities should be done by using various visual elements reflecting the cultural and heritage. There are problems faced by teachers regarding historical cultural heritage education. As a result of the interviews, almost half of the teachers stated that they face problems related to lack of material. Besides, models, posters etc. made about historical cultural heritage elements. Stated that there is not enough space in schools to store visual material products and therefore it is a problem to access the material related to the course. Some of the teachers have stated that narration is theoretical and therefore abstract. Another problem is that teachers do not prefer trips to museums and historical sites such as historical cultural heritage and rich areas because of the high number of procedures for permission. Most of the teachers stated that they should be taught in the social studies course, but they could be taught in other courses instead of being compressed to only one course. There are also Turkish teachers who argue that this subject is appropriate. The teachers stated that these elements can be included in the reading texts in the Turkish course. Some teachers also stated that in the course of technology and design, activities can be done on subjects related to historical cultural heritage both in drawing

| Kastamonu Eğitim Dergisi, 2020, Vol. 28, No. 31 
and model preparation. Teachers expressed their views on the historical cultural heritage elements of Denizli, which is similar to the question about the historical cultural heritage elements, in the form of Hierapolis Ancient City, Leodikya Ancient City, Buldan Historical Houses, local dishes, Zeybek play, Atatürk Ethnography Museum and Works. 


\section{GíRiş}

Kültür insanın ve insan topluluklarının hayat tarzını ve sosyal problemlere ürettikleri çözümleri ifade eder. Bu nedenle kültürü meydana getiren unsur insanlar ve toplumun kendisidir. Her toplumun kendine has bir kültürü vardır ve bu kültür onu ötekilerden ayırır. Bunun yanında kültür, bir toplumda öğrenme yoluyla nesilden nesle aktarılarak, zaman içinde değişebilmektedir (Günay, 2005, s. 28). İnsanlar, yerleştikleri mekânlarda kültürler oluşturmuşlardır. Sahip oldukları bu kültürleri kendileriyle birlikte yaşatırken üzerine birçok kültür daha ekleyerek zenginleştirip gittikleri her yere taşımışlardır (Öcal, 2014). İnsanın yaşadığı zaman dilimleri içerisinde, geçmiş birikimlerden yararlanarak zenginleştirdiği ve gelecek nesillere aktararak sürekliliğini sağladığı veriler dizisi tarihi kültürel mirasları oluşturmaktadır (Çankaya, 2006).

Tarihi kültürel miraslar, anlatılacak güçlü hikâyelere sahiptir. Tarihi kültürel miraslar plan ve tasarımlar, yapı malzemeleri, ortam ve uyumu, eşyalar ve içerdikleri diğer nesneler ile yakından ilgilidir (Harper, 1997). Uygarlıkların nasıl bir geçmişe sahip oldukları, sosyal ve ekonomik hayatları hakkında bilgileri bize tarihi kültürel miras ögeleri verir. Tarihi kültürel miras ögeleri toplumun kökleşmesinde ve kültürleri benimseyerek toplumsallaşmasında etkilidir (Artun, 2005). Tarihi kültürel mirasların bir değeri olduğu inancından dolayı, korunarak gelecek nesillere aktarılması önemli bir konudur. Tarihi kültürel miras ögelerinin diğer önemli yanı da toplum ve geçmiş arasında bağlantı kurarak, bu topluluğun varlığına delil olmaktadır. Kitaplarda soyut kalan geçmişteki olayları somutlaştırmada tarihi kültürel miras ögeleri yardımcı olmaktadır. Çünkü bu ögeler geçmişin izlerini günümüze kadar getirmişlerdir (Aksoy ve Enlil, 2012).

Her toplum için kültür ve kültürel miraslar önemli kaynaklardır. Yaşayan toplumun gelenekleri, aynı alanı paylaşan eski toplumların yaşayışlarını gösteren maddi bir belirti veya sembol olarak düşünülür. Kültürel miraslar ebedi değildir. Kültürel miraslar yüzlerce hatta binlerce yıldır hayatta kaldıkları için insanlar tarafından bunların sonsuza kadar yaşayacakları düşünülmektedir. Aslında zamanla kültürel miraslarda fiziksel, biyolojik ve kimyasal değişimler sonucu bozulmalar meydana gelmektedir (Aslan ve Ardemagni, 2006). Dünya genelinde artan baskı, silahlı çatışma, ticaret ve yağma gibi nedenlerden dolayı, kültürel miras alanlarına yönelik tehditler de artmaktadır (Smith, Messenger ve Soderland, 2010). Kültürel mirasın yok olması sadece kültürel mirası harap olan insanlara değil, aynı zamanda insanlığın ortak tarihi için de bir kayıptır (Sokal, 2006).

Arkeolojik alanlar ve insan yapımı yapılar ve toplumun kullandığı ögeler geçmişin korunması gereken önemli delilleridir (Prott ve Patrick, 1992). Tarihi kültürel miras ögeleri kendinden sonra gelen nesillere, ortaya çıktıkları zamanı gösteren belgelerdir (Akay, 2006). Bu nedenle tarihi kültürel miras ögeleri konusunda her nesil bilgilendirilmelidir. Bilgilendirme de en güzel okullarda eğitimle yapılır. Çünkü her medeniyet hayatını eğitime borçludur (Durant, 1978). Nitekim 1739 sayılı Milli Eğitim Temel Kanunu'nda Türk milletinin milli, ahlaki, insani ve manevi değerlerini benimseyen, koruyan, geliştiren bilgiyi üreten kullanan yeniliklere açık ve milli bilinci koruyan yurttaşların yetişmesi için her derece ve türdeki ders programlarında kültürümüzün korunup geliştirilmesine sağlayacak eğitimin verilmesi gerektiği vurgulanmıştır (Milli Eğitim Bakanlığı [MEB], 2005). Tarihi kültürel miras eğitimi, bir toplumun tarihi mimarlık, müzeler ve tarihi kentler, kültürel peyzajlar ve sokak görünümleri, şehitlikler, gelenekler, fotoğraflar, gazeteler, dokümanlar, mahkeme kayıtları, aile belgeleri, hatıratlar, el ürünleri ve objeleri içeren bütün yönlerinin korunmasını, ilgi görmesini ve öğrenilmesini içerir. Tarihi kültürel miras eğitimi verilirken öncelikle çocuğun yakın çevresinden örneklerle bu konu somutlaştırılması ve bu konuda çocuğun bilgisinin artırtılması bu eğitimin en önemli özelliğidir. Bu örnekleri inceleyen çocuklarda, farklı zamanlarda yaşayan toplumların değişik özelliklerini yorumlayabilme becerisi ortaya çıkar. Bunun sonucunda, çocuklar, geçen zamana rağmen ayakta kalan tarihi kültürel miras ögelerini görerek bu ögeleri koruma ve sürekliliğini sağlama yönünde bilinçlenirler. Bunun yanında gittikleri farklı bölgelerdeki tarihi kültürel miras ögelerini de inceleyip kıyaslama yapılarak her toplumun geçmiş belleğini ve diğerlerinden ayırt edici özelliklerini ortaya çıkarırlar. Ayrıca bu tarihi kültürel miras eğitimi sayesinde ortaya çıkan bu bilinçle çocuklar sadece kendi miras ögelerini değil evrensel miras ögelerini de tanımış olurlar (Avcı ve Memişoğlu, 2016).

Tarihi kültürel miras eğitimi bireyin çevreyle etkileşime girdiği anda başlar. Aile içerisinde büyüklere sorulan sorularla, oturulan ev, semt ya da şehirle ilgili sorularla, ya da alışverişe giderken görülen bir heykele dair anneye sorduğu sorularla, çocuğun kültürel mirasa dair ilk temelleri de atılmış olur (Çulha Özbaş, 2014, s.746). Buradan da anlaşılacağı üzere tarihi kültürel miras ögelerini nesilden nesle aktarmak her bireyin en önemli görevlerinden biridir. Tarihi kültürel miras ögelerini doğru şekilde anlamak, korumak, yaşatmak ve çocuklarda koruma bilincini geliştirmek gerekir. Bu da ancak iyi bir eğitimle gerçekleşebilir (Avcı ve Memişoğlu, 2016).

Kültür konusunu doğrudan ele alan toplumsal disiplinlerin başında gelen Sosyal Antropoloji ve Etnoloji bilimleri, insan topluluklarının maddi ve manevi kültürleri üzerinde çalışmalar yapar. Bunların yanında Etnografya bilimi ise bir toplumun kültürel gelişim içerisinde yarattığı maddi ve manevi kültür ürünlerini inceler (Başar, 1994, s. 225). Bunların yanında, geçmişteki uygarlıkların kültürünü incelediği için tarih bilimi; kültürün davranış üzerindeki etkisini incelediği için psikoloji ve kültürün toplumsal yapıya olan etkisini incelediği için sosyoloji kültür konusunu ele alan diğer bilimlerdir. Sosyal bilgiler dersi disiplinler arası bir çalışma alanı olduğu için bu bilimlerin hepsinden yararlanmaktadır. Bu bilimlerde verilen kültür konusu sosyal bilgiler dersi bünyesinde öğrencilere aktarılmaktadır. Çulha Özbaş’a göre (2014, s. 746) somut ya da somut olmayan kültürel miras ögelerini öğrencilerin karşısına çıkaracak derslerden biri sosyal bilgiler dersidir. Sosyal bilgiler dersinin konusu insan, insanın yaşadığı çevresi ve toplumla ilgilidir. Bunun yanında kültürün de insan eliyle oluşturulan her şey olmasından dolayı sosyal bilgilerle kültür arasında bir bağ vardır (Sertkaya, 2010, s. 40). Sosyal bilgiler dersinde öğrencilerin geçmişini öğrenmeleri, kendi kültürleriyle diğer kültürleri karşılaştırarak tanımaları ve geçmişlerinden mutluluk duymaları önemlidir (Ulusoy, 2009). Bu doğrultuda tarihi kültürel miraslar mekân ve zaman üzerinde bağlantılar kurarak, empatik anlayış kazandırır. Bu yerler çocukların düşünme becerilerini ve gözlemleme, veri toplama,

| Kastamonu Eğitim Dergisi, 2020, Vol. 28, No. 31 
benzetme, karşılaştırma, analiz ve sentez yapma, kanıtları değerlendirme, hipotez kurma ve sonuca varma gibi düşüncelerini de geliştirir (Yeşilbursa, 2008, s. 211).

Tarihi kültürel miras eğitimi en fazla ilköğretimde sosyal bilgiler dersi ile 'Kültür ve Miras' öğrenme alanı içinde verilmektedir. Bu öğrenme alanıyla öğrenciler, Türk kültürünü oluşturan unsurları ve bunların tarihsel kökenlerini inceleme fırsatı bulabilmektedirler. Ayrıca milli bilincin oluşmasında önemli bir yere sahip olan kültürel unsurları ve gelişim süreçlerini kavrayarak, kültürel mirasın korunması ve geliştirilmesi konusunda duyarlılık kazanabilmektedirler. Ayrıca bugün sahip olduğumuz kültürün uzun bir geçmişin eseri olduğunu görülmektedir (Çulha, 2006-2007). Sosyal bilgiler dersi öğretim programında yer alan genel amaçlarda bazı maddeler öğrencilerde kültürel miras bilincini oluşturmada doğrudan ya da dolaylı olarak ilgilidir. Bu amaçlar programda şöyle verilmiştir.

- Türk kültürünü ve tarihini oluşturan temel öge ve süreçleri kavrayarak, milli bilincin oluşmasını sağlayan kültürel mirasın korunması ve geliştirilmesi gerektiğini kabul eder.

- Farklı dönem ve mekânlara ait tarihsel kanıtları sorgulayarak insanlar, nesneler, olaylar ve olgular arasındaki benzerlik ve farklılıkları belirler, değişim ve sürekliliği algılar.

- İnsanlığın bir parçası olduğu bilincini taşıyarak, ülkesini ve dünyayı ilgilendiren konulara duyarlılık gösterir (MEB, 2005).

Tarihi kültürel miras eğitiminin verilmesi ve geleceğin emanetçisi öğrencilerde bu bilincin oluşması son derece önemlidir. Bunun içinde disiplinler arası bir yaklaşımla seçilip oluşturulan bilgileri ve temel kültür ögelerini içinde barındıran ders olan sosyal bilgiler dersinden (Sözer, 1998) faydalanmak gerekir. Özbaş (2012) da tarihi kültürel miras eğitimini en iyi sunacak ve öğrencileri bilgilendirecek olan dersin sosyal bilgiler olduğunu belirtmiştir. Bu nedenlerden dolayı dersin uygulayıcıları olan sosyal bilgiler öğretmenlerinin bu konun bilincinde olmaları gerekmektedir.

Alanyazın incelendiğinde, (Deveci, 2009; Sidekli ve Karaca, 2013; Yalçınkaya, 2015; Yeşilbursa ve Barton, 2011; Yeşilbursa ve Uslu, 2014) sosyal bilgiler öğretmen adayları ve (Arıkan, 2012; Aslan ve Çulha, 2008; Dönmez ve Yeşilbursa, 2014; Gökkaya ve Yeşilbursa, 2009; Selanik Ay ve Deveci, 2011; Ünlü, 2012) öğrencilere yönelik araştırmalar yapıldığı görülmüştür. Ancak alanyazında uygulamanın içinde bulunan sosyal bilgiler öğretmenlerine yönelik bir araştırmaya rastlanmamıştır. Bu nedenle sosyal bilgiler öğretmenlerinin tarihi kültürel miras ögeleri konusundaki görüşleri, sosyal bilgiler dersi ile tarihi kültürel miras eğitiminin ilişkisinin ne olduğu, sosyal bilgiler dersinde tarihi kültürel miras eğitimine yeterince yer verilip verilmediği, tarihi kültürel miras eğitimi verilirken hangi yöntem ve teknikleri kullanılabileceği ve tarihi kültürel miras eğitimi verilirken karşılaşılan sorunların neler olduğu ile ilgili görüşleri ortaya çıkarılmak istenmektedir. Böylece bu araştırmadan çıkan bulgular neticesinde tarihi kültürel miras eğitimine yeni bir bakış açısı kazandırmak amaçlanmaktadır. Bu amaç doğrultusunda aşağıdaki sorulara cevap aranmıştır:

1. Öğretmenlere göre tarihi kültürel miras ögeleri neleri kapsamaktadır?

2. Tarihi kültürel miras eğitiminin sosyal bilgiler eğitimi ile ilişkisi hakkında öğretmenlerin düşünceleri nelerdir?

3. Tarihi kültürel miras eğitimi konusuna sosyal bilgiler programında yeterince yer verilip verilmediği hakkında öğretmenlerin düşünceleri nelerdir?

4. Öğretmenlere göre sosyal bilgiler dersinde tarihi kültürel miras eğitimi hangi yöntem ve teknikler kullanılarak anlatılabilir?

5. Öğretmenler sosyal bilgiler dersinde tarihi kültürel miras eğitim verilirken hangi sorunlarla karşılaşmaktadır?

6. Öğretmenlere göre tarihi kültürel miras eğitimi hangi derslerde verilmelidir? Neden?

7. Öğretmenlere göre Denizli ilinin tarihi kültürel miras ögeleri nelerdir?

\section{YÖNTEM}

Bu bölümde araştırma modeli, çalışma grubu, verilerin toplanması ve verilerin analizi başlıkları ele alınmıştır.

\section{Araştırmanın Modeli}

$\mathrm{Bu}$ araştırma nitel araştırma yaklaşımına uygun olarak tasarlanmıştır. Nitel araştırmada amaç; derinlemesine betimleme, yorumlama, bireyin bakış açısını anlamadır. Nitel araştırma yöntemlerinden biri fenomenolojik (olgubilim) desenidir (Fraenkel ve Wallen, 2006'dan aktaran Sözen, 2013). Farkında olduğumuz ancak derinlemesine ve ayrıntılı bir anlayışa sahip olmadığımız olgular için fenomenoloji deseni kullanılır (Büyüköztürk ve diğerleri, 2011, s. 19). Fenomenolojik araştırmalar öğretmenlerin deneyimlerini paylaşmasına ve araştırmacılara bu deneyimlerin anlamlarını tanımlayabilmelerini sağlar (Lester, 1999'dan aktaran Sözen, 2013).Fenomenoloji deseni, sosyal bilgiler öğretmenlerinin tarihi kültürel miras eğitimine ilişkin görüşlerini almak için kullanılmıştır.

\section{Çalışma Grubu}

Bu araştırmaya 2016-2017 öğretim yılında Denizli iline bağı Merkezefendi ve Pamukkale ilçelerinde bulunan 12 ortaokulda görev yapan, 10 erkek ve 10 kadın olmak üzere 20 sosyal bilgiler öğretmeni katılmıştır. Çalışmada amaçlı örneklem modeli kullanılmıştır. Amaçlı örnekleme, zengin bilgiye sahip olduğu düşünülen durumların derinlemesine çalışılmasına olanak verir. Bu anlamda, amaçlı örnekleme yöntemi pek çok durumda, olgu ve olayın keşfedilmesinde ve açıklanmasında yararlı olur (Patton, 1987'den aktaran Yıldırım ve Şimşek, 2013, s. 135). 


\section{Verilerin Toplanması}

Sosyal bilgiler öğretmenlerinin tarihi kültürel miras eğitimine ilişkin görüşlerini ortaya çıkarmak amacıyla alanyazından yararlanılarak araştırmacılar tarafından "Sosyal Bilgiler öğretmenlerinin tarihi kültürel miras eğitimine ilişkin görüşleri" adlı yarı yapılandırılmış bir görüşme formu geliştirilmiştir. Görüşme formunda yer alan soruların açık ve anlaşılırlığı konusunda uzman görüşüne sunulmuştur. Gelen eleştiriler doğrultusunda, başta sekiz tane hazırlanan görüşme soruları yediye indirilerek son şekli verilmiştir. Araştırma verileri öğretmenlerle yapılan görüşmeler ile 2017 yılı Şubat ayında toplanmıştır. Görüşmeler her bir katılımcı için yaklaşık olarak 30 dakika sürmüş olup okulda gerçekleştirilmiştir. Görüşme yönteminin kullanılmasının nedeni, bireylerin verilerini, görüşlerini, deneyimlerini ve duygularını ortaya çıkarma yönünden oldukça güçlü olması ve iletişimin en yaygın biçimi olan konuşmayı temel almasındandır (Yıldırım ve Şimşek, 2013, s. 155).

\section{Verilerin Analizi}

Görüşmelerden elde edilen veriler için içerik analizi yöntemi kullanılmıştır. İçerik analizinde temel amaç, toplanan verileri açıklayabilecek kavramlara ve ilişkilere ulaşmaktır. İçerik analizinde veriler dört aşamada analiz edilmektedir (Yıldırım ve Şimşek, 2013, s. 259-260):

- Verilerin kodlanması

- Temaların bulunması

- Kodların ve temaların düzenlenmesi

- Bulguların tanımlanması ve yorumlanması

Araştırmanın amaçları çerçevesinde verilerin çözümlenmesinde kullanmak amacıyla kod listesi oluşturulmuştur. Kod listesinden yararlanarak veriler çözümlenmiş ve temalara ulaşılmıştır. Görüşmeye katılan 20 öğretmene kişisel bilgilerin gizliliği kapsamında kod isimler (Ö1, Ö2...) verilmiştir. Doğrudan alıntılarda öğretmenlerin kod isimleri kullanılmıştır.

\section{Geçerlik ve Güvenirlik Çalışması}

Araştırmanın iç geçerliğini sağlamak amacıyla uzman ve katılımcı görüşü alınmıştır. Toplanan veriler, verilerin analizi ve sonuçlar araştırma sürecinde uzman incelemesine sunulmuştur. Uzmanlardan gelen geri bildirimler ve öneriler dikkate alınmıştır. Görüşme sonunda toplanan veriler özetlenmiş ve katılımcılardan bunların doğruluğuna ilişkin düşünceleri alınmıştır. Araştırmadan elde edilen verilerin ve bunlara ilişkin araştırmacının ulaştığı sonuçların ve yorumların veri kaynakları ile teyit edilmesinde yarar vardır (Yıldırım ve Şimşek, 2013, s. 302). Araştırma sonuçlarının "aktarılabilirliğini” arttırmak için iki yöntem bulunmaktadır. Bunlar; ayrıntılı betimleme ve amaçı örneklemedir. Ayrıntılı betimleme nedeniyle elde edilen veriler doğrudan alıntılar yapılarak sunulmuştur. Ayrıntılı betimleme ham verinin ortaya çıkan kavram ve temalara göre yeniden düzenlenmiş bir biçimde okuyucuya yorum katmadan ve verinin doğasına mümkün olduğu ölçüde sadık kalınarak aktarılmasıdır (Erlandson, Harris, Skipper ve Allen 1993' ten aktaran Yıldırım ve Şimşek, s. 304). Doğrudan alıntılar bu amaçla araştırmacılar tarafından sık kullanılır (Yıldırım ve Şimşek, 2013, s. 304).

Araştırmanın tutarlılı̆ını sağlamak amacıyla araştırma sorusu açık bir biçimde ortaya konmuş ve araştırmanın tüm aşamasında araştırma sorusuna bağlı kalınmıştır. Veri toplama araçlarının oluşturulması, verilerin toplanması ve analizi aşamasında tutarlı davranmaya dikkat edilmiştir. Araştırmanın güvenirliği, Miles ve Huberman (1994)'ın formülü (Güvenirlik = Görüş Birliği / Görüş Birliği + Görüş Ayrıı̆̆ı x 100) kullanılarak hesaplanmıştır. İki farklı uzmanın yapmış olduğu kodlamalar arasındaki tutarlılık toplamda $\% 89$ olarak belirlenmiştir.

\section{BULGULAR}

Araştırmanın birinci alt amacı olan “Öğretmenlere göre tarihi kültürel miras ögeleri neleri kapsamaktadır?” sorusuna ilişkin sekiz temaya ulaşılmış, bu temalar Tablo 1'de verilmiştir.

Tablo 1. Öğretmenlerin tarihi kültürel miras ögelerinin neleri kapsadığı ile ilgili görüşleri

\begin{tabular}{lcccc}
\hline Temalar & Erkek & Kadın & $\mathrm{f}$ & $\%$ \\
\hline Gelenek ve Görenekler & 4 & 6 & 10 & 16,39 \\
Tarihi Eserler & 8 & 9 & 17 & 27,86 \\
Sözlü Eserler & 2 & 2 & 4 & 6,55 \\
Yazılı Eserler & 1 & 1 & 2 & 3,27 \\
Düğünler & 2 & 1 & 3 & 4,91 \\
Milli Değerler & 4 & 10 & 16,39 \\
Mimari Yapıtlar & 5 & 6 & 11 & 18,03 \\
Halk Oyunları & 2 & 2 & 4 & 6,55 \\
\hline
\end{tabular}

Tablo 1'de görüldüğü gibi, tarihi kültürel miras ögelerinin neleri kapsadığı ile ilgili olarak sosyal bilgiler öğretmenleri \% 27,86 'sı tarihi eserler, \%18,03'ü mimari yapıtlar, \% 16,39'u milli değerler ve gelenek ve görenekler, \% 6,55'i sözlü eserler ve halk oyunları, 
\% 4,91'i düğünler, \% 3,27'si ise yazılı eserler olduğunu belirtmişlerdir. Araştırmaya katılan öğretmenlerden biri tarihi kültürel miras ögeleri için kaynağını geçmişten alan değerler olduğunu ve bununla ilgili örneklerini şu şekilde vermiştir:

"Tarihi kültürel miras ögeleri adı üstünde tarihten gelen gelenek, görenek, folklor gibi kültürel değerleri kapsar."(Ö1).

Araştırmaya katılan bir diğer öğretmen de daha çok mimari yapıtlardan ve yazılı eserlerden örnekler vermiştir:

"Camiler, türbeler, medreseler, kervansaraylar, hamamlar, müzelerdeki nesneler, antik tiyatrolar, saraylar, edebi

eserler tarihi kültürel miras ögelerimizdendir."(Ö13).

Ö19 kod isimli öğretmen de tarihi kültürel miras ögelerini genel bir şekilde gruplandırarak şu şekilde belirtmiştir:

“Geçmişten günümüze ulaşmış olan doğal ve tarihi yapıtların tümünü kapsar."(Ö19).

Tarihi kültürel miras ögelerinin neleri kapsadığı ile ilgili öğretmen görüşlerine verilen cevaplara bakıldığında öğretmenlerin bu ögelerle ilgili farkındalık sahibi olduğu söylenebilir.

Araştırmanın ikinci alt amacı olan "Tarihi kültürel miras eğitiminin sosyal bilgiler eğitimi ile ilişkisi hakkında öğretmenlerin düşünceleri nelerdir?" sorusuna ilişkin üç temaya ulaşılmış, bu temalar Tablo 2'de verilmiştir.

Tablo 2. Öğretmenlerin Tarihi Kültürel Miras Eğitiminin Sosyal Bilgiler Eğitimi İle ilişskisi Hakkındaki Görüşleri

\begin{tabular}{|c|c|c|c|c|}
\hline Temalar & Erkek & Kadın & f & $\%$ \\
\hline Sosyal Bilgiler Disiplinlerarası Olduğu için & 6 & 8 & 14 & 42,42 \\
\hline Sosyal Bilgiler Toplumla illişkili Olduğu İçin & 8 & 9 & 17 & 51,51 \\
\hline Sosyal Bilgilerin Amaçlarında Yer Aldığı İçin & 1 & 1 & 2 & 6,06 \\
\hline
\end{tabular}

Tablo 2'de görüldüğü gibi tarihi kültürel miras eğitiminin sosyal bilgiler dersiyle ilişkisi konusundaki görüşler üç tema altında toplanmıştır. Öğretmenlerin \% 51,51'i sosyal bilgiler dersinin toplumla ilişkisi nedeniyle tarihi kültürel miras ögelerinin de toplum olarak hayatımızın önemli bir yerinde bulunmasından dolayı bağlantılı olduğunu belirtmişlerdir. Buna yakın olarak \% 42,42 ile sosyal bilgiler dersinin disiplinlerarası bir ders olduğu ve bu yüzden tarihi kültürel miras eğitimi konusunun sosyal bilgiler eğitiminde yer alması gerektiği yönünde öğretmenlerin görüşleri yer almıştır. \% 6,06'lık bir kısım ise tarihi kültürel miras eğitiminin sosyal bilgiler dersinin amaçları içerisinde yer almasından dolayı ilişkili olduğunu belirtmişlerdir. Araştırmaya katılan öğretmenlerden biri tarihi kültürel miras eğitimi ile sosyal bilgiler dersi arasındaki ilişkinin, sosyal bilgiler programında yer alan amaçların arasında kültür konusunun yer almasından dolayı olduğunu şu şekilde belirtmiştir:

"Sosyal bilgiler dersinin konusudur ve sosyal bilgiler dersinin amaçları arasında yer almaktadır."(Ö5).

Başka bir öğretmen ise sosyal bilgiler dersinin konusunu toplumdan aldığı için, toplumsal bir konu olan kültür konusuyla dolayısıyla kültürel mirasla da ilişkili olduğunu belirtirken şu cümleyi kullanmıştır:

"Sosyal bilgiler ile tarihi kültürel miras eğitimi ayrılmaz bir bütündür. Sosyal bilgiler dersinin konuları toplumu her anlamda kapsayan konulardır bu konuda toplumsal bir konu olduğu için iç içedir."(Ö8).

Öğretmenlerin bazılarının görüşlerine göre, sosyal bilgiler dersi disiplinlerarası bir ders olmasından dolayı tarihi kültürel miras, kültür ve tarihi kültürel miras eğitimiyle ilgili konuları da bünyesinde barındırdığı için ilişkili olduğunu şöyle belirtmişlerdir:

"Sosyal bilgiler dersi disiplinlerarası bir derstir. Bu nedenle tarihi kültürel miras eğitimi de sosyal bilgiler dersiyle ilişkilidir."(13).

"Sosyal bilgiler dersi verilerini sosyal bilimlerden alıyor. Bu nedenle tarihi kültürel miras eğitimi birçok sosyal bilim derslerini içermesinden çok bunların hepsini bünyesinde toplayan sosyal bilgiler dersinde verilmesi uygundur."(Ö14).

Tarihi kültürel miras eğitiminin sosyal bilgiler dersiyle ilişkisi konusundaki görüşlere bakıldığında öğretmenlerin sosyal bilgiler dersinin amacı, önemi, içeriği hakkında bilgi sahibi olduklarına ulaşılabilir.

Araştırmanın üçüncü alt amacı olan "Tarihi kültürel miras eğitimi konusuna sosyal bilgiler programında yeterince yer verilip verilmediği hakkında öğretmenlerin düşünceleri nelerdir?" sorusuna ilişkin iki ana tema altında yer alan temalara ulaşılmış, bu temalar Tablo 3'te verilmiştir.

Tablo 3. Öğretmenlerin Sosyal Bilgiler Programında Tarihi Kültürel Miras Eğitimine Yeterince Yer Verilip Verilmediği Hakkındaki Görüşleri

\begin{tabular}{|c|c|c|c|c|}
\hline Temalar & Erkek & Kadın & $\mathrm{f}$ & $\%$ \\
\hline Yeterince Yer Verilmiştir & 14 & 14 & 28 & 33,33 \\
\hline 5. sınıfta yer verilmiştir & 5 & 4 & 9 & 10,71 \\
\hline Programda yer verilmiştir & 1 & 2 & 3 & 3,57 \\
\hline Bütün sınıf düzeylerine serpiştirilmiştir & 2 & 3 & 5 & 5,95 \\
\hline Kalıcı olmamaktadır & 3 & 3 & 6 & 7,14 \\
\hline Yaş düzeyi uygun değildir & 1 & 1 & 2 & 2,38 \\
\hline Ders saati yeterli değildir & 2 & 1 & 3 & 3,57 \\
\hline Yeterince Yer Verilmemiştir & 9 & 5 & 14 & 16,66 \\
\hline 6 ve 7. Sınıflarda az yer verilmiştir & 4 & 4 & 8 & 9,52 \\
\hline
\end{tabular}




\begin{tabular}{lcccc}
\hline Temalar & Erkek & Kadın & $\mathrm{f}$ & $\%$ \\
\hline Ayrı ders olarak verilmelidir & 1 & 0 & 1 & 1,19 \\
Detaylandırılmalıdır & 4 & 1 & 5 & 5,95 \\
\hline
\end{tabular}

Tablo 3’te belirtildiği gibi sosyal bilgiler programında tarihi kültürel miras eğitimine yeterince yer verilip verilmediği ile ilgili araştırmaya katılan öğretmenlerin görüşlerine bakıldığında programda yer verilmiş olmasına rağmen yetersiz olduğu görülmektedir. Örneğin, öğretmenlerin, \%33,33 yeterince yer verildiğini düşünürken bunlardan \%7,14'ü kalıcı olmadığını \%2,38'i sadece 5. sınıfta ağılıklı verilmesinin yaş düzeyine uygun olmadı̆̆ını \%3,57'si de programda yeterli olmasına rağmen ders saatinin yeterli olmadığını belirtmişlerdir. Yeterince yer verilmediği şeklinde görüş bildiren \% 16,66 oranındaki öğretmenden \%9,52'si 6 ve 7. sınıflarda az yer verildiğini, $\% 5,95$ 'i ise kavramsal olarak kaldığını, detaylandırılmadığını belirtmektedir. \%1,19 'u ise yeterli olmadığının yanında bu dersin tamamen ayrı bir ders olarak öğrenciye verilmesi gerektiğini belirtmiştir. Öğretmenlerin bazıları görüşlerinde, tarihi kültürel miras eğitiminin sınıf düzeylerine göre sosyal bilgiler dersinde oransız dağıtıldığını şu şekilde belirtmiştir:

"5. sınıflarda tarihi kültürel miras eğitiminden yoğun şekilde bahsediliyor fakat 6 ve 7. sınıflarda bu konuya az yer verilmektedir."(Ö1).

"Tarihi kültürel miras eğitimi konusu yeterince yer verilmemiştir. 5. Sınıflarda yoğun şekilde yer verilmiştir fakat bu sınıf düzeyi bu konuları kavrayabilecek olgunlukta değildir bu nedenle üst kademelerde bu konuya ağırlık verilmelidir."(Ö7).

Ö4 kod isimli öğretmen tarihi kültürel miras eğitiminin sosyal bilgiler dersinde yeterince yer verildiğini belirtenlerden biridir. Fakat yine de bazı aksaklıkların olduğunu şu şekildi belirtmiştir:

"Tarihi kültürel miras eğitimi konusuna yeterince yer veriliyor. Fakat süre yetersiz olduğu için detayına inemiyoruz."(Ö4).

Öğretmenlerden biri tarihi kültürel miras eğitiminin sosyal bilgiler dersinde yeterince yer verilmemesinin yanında sürenin yetersizliğinden dolayı teorik işlendiğini bu nedenle öğrencide soyut kaldığını belirtmiştir. Bunun yanında bu konuya şu şekilde bir öneri getirmiştir:

"Tarihi kültürel miras eğitimi konusuna sosyal bilgiler dersinde yeterince yer verilmemekle birlikte süre yetersizliğinden soyut olarak anlatılıyor ve kalıcı olmuyor. Bu nedenle bu konu ayrı bir ders olarak verilmelidir."(Ö6).

Ö9 kod isimli öğretmen tarihi kültürel miras eğitimine sosyal bilgiler dersinde yeterince yer verilip verilmediği konusundaki düşünceleri geniş bir bakış açısından bakarak şu şekilde belirtmiştir:

"Tarihi kültürel miras eğitimi konusuna yeterince yer verilmesi nerden bakıldığına göre değişir. Örneğin programda yer veriliyor fakat öğrencilerin bu konuyu içselleştirmeleri boyutunda yeterince yer verilmiyor. Bunun nedeni müfredat yoğunluğu olabilir."(Ö9).

Öğretmenlerin görüşlerine bakıldığında, sosyal bilgiler dersi öğretim programında tarihi kültürel miras eğitimine yer verilmesi gerektiği konusunda hemfikir oldukları görülmektedir.

Araştırmanın dördüncü alt amacı olan “Öğretmenlere göre sosyal bilgiler dersinde tarihi kültürel miras eğitimi hangi yöntem ve teknikler kullanılarak anlatılabilir?" sorusuna ilişkin 2 ana tema altında yer alan temalara ulaşılmış, bu temalar Tablo 4 'te verilmiştir.

Tablo 4. Öğretmenlerin Tarihi Kültürel Miras Eğitimi Anlatılırken Hangi Yöntem ve Tekniklerin Kullanılacağı Hakkındaki Görüşleri

\begin{tabular}{lcccc}
\hline Temalar & Erkek & Kadın & $f$ & $\%$ \\
\hline Sınıf Dışı Etkinlikler & 6 & 12 & 18 & 21,42 \\
Sözlü Tarih & 1 & 0 & 1 & 1,19 \\
Müze gezileri & 0 & 3 & 3 & 3,57 \\
Gezi Gözlem & 5 & 9 & 14 & 16,66 \\
Sını́ İ̧̧i Etkinlikler & 8 & 16 & 24 & 28,57 \\
Soru Cevap & 0 & 3 & 3 & 3,57 \\
Sunuş Yöntemi & 0 & 1 & 1 & 1,19 \\
Beyin Fırtınası & 0 & 1 & 1 & 1,19 \\
Münazara & 0 & 1 & 4 & 1,19 \\
Drama & 0 & 4 & 4 & 4,76 \\
Sanal Müze & 3 & 1 & 10 & 4,76 \\
Görsel Materyal Kullanımı & 5 & 5 & 11,90 \\
\hline
\end{tabular}

Tablo 4'te görüldüğü gibi tarihi kültürel miras eğitimi konusu anlatılırken kullanılabilecek yöntem ve teknikler sınıf içi ve sınıf dışı etkinlikler şeklinde iki ana tema altında verilmiştir. Sınıf dışı etkinliklerden olan gezi gözlem yöntemini öğretmenlerin \% 16,66 'sı tercih ederken, \% 3,57'si müze gezilerini, \% 1,19'u ise sözlü tarih yöntemini tercih etmişlerdir. \% 11,90'ı sınıf içi etkinliklerden olan görsel materyal kullanımı belirtilmiştir. Bunun yanında \% 4,76'sı drama ve sanal müze yöntemini, \% 3,57'si soru cevap tekniği, \% 1,19’u sunuş yöntemi, beyin fırtınası, münazara yöntemlerinin uygun olduğunu belirtmişlerdir. Bu soru hakkındaki öğretmenlerin görüşlerinden bazıları şunlardır: 
Ö8 kod isimli öğretmen tarihi kültürel miras eğitimi kapsamında yapılan gezilerde eşlik eden rehberlerin öğrencinin düzeyine göre tanıtım yapması gerektiğini şöyle belirtmiştir:

"Öğrencilerin bulunduğu bölgedeki tarihi kültürel miras alanlarına geziler düzenleyerek çocukların yaş düzeyine uygun şekilde buralar anlatılabilir."(Ö8).

Öğretmenlerden biri ise tarihi kültürel miras eğitiminde gezi gözlem tekniğinin kullanılması gerektiğini ama imkân olmadığında da sanal müze ile bu eksiğin kapatılabileceğini şu şekilde belirtmiştir:

"En güzel yöntem gezerek, görerek, dokunarak yapılandır ancak buna imkân olmadığı durumlarda ise sanal müze ile bu sağlanabilir."(Ö9).

Ö19 kod isimli öğretmen öğrenciyi aktif tutarak etkinlikler yapılması gerektiğini belirtmiştir. Bunun içinde şu yöntem ve tekniklerin kullanılması görüşündedir:

"Drama, sunum, sunuş yöntemi kullanılarak anlatılabilir. Bunun yanında görsel materyallerden de yararlanılabilir."(Ö19).

Tarihi kültürel miras eğitiminin anlatımında öğretmenlerin görüşlerine bakılırsa, daha çok görerek, dokunarak, hissederek dersin işlenebileceği yöntem ve teknikler tercih edilmiştir denilebilir.

Araştırmanın beşinci alt amacı olan “Öğretmenler sosyal bilgiler dersinde tarihi kültürel miras eğitim verilirken hangi sorunlarla karşılaşmaktadır?" sorusuna ilişkin 4 ana tema altında yer alan temalara ulaşılmış, bu temalar Tablo 5'te verilmiştir.

Tablo 5. Öğretmenlerin Tarihi Kültürel Miras Eğitimi Verirken Hangi Sorunlarla Karşılaştığı Konusundaki Görüşleri

\begin{tabular}{|c|c|c|c|c|}
\hline Temalar & Erkek & Kadın & $f$ & $\%$ \\
\hline Okul Yönetimi İle İlgili Sorunlar & 9 & 6 & 15 & 23,43 \\
\hline Gezi İzinlerinin Kolay Alınamaması & 4 & 1 & 5 & 7,81 \\
\hline Materyal Eksikliği & 5 & 5 & 10 & 15,62 \\
\hline Öğrenci İle İlgili Sorunlar & 2 & 4 & 6 & 9,37 \\
\hline Öğrencilerin İlgisiz Olması & 2 & 2 & 4 & 6,25 \\
\hline Öğrencilerde Anakronizm Sorunu & 0 & 1 & 1 & 1,56 \\
\hline Farklı Kültürel Mirasları Benimsememesi & 0 & 1 & 1 & 1,56 \\
\hline Ders ille İlgili Sorunlar & 4 & 8 & 12 & 18,75 \\
\hline Kitapların yetersiz kalması & 1 & 1 & 2 & 3,12 \\
\hline Sürenin Yetersiz Olması & 0 & 4 & 4 & 6,25 \\
\hline Anlatımın Soyut Kalması & 3 & 3 & 6 & 9,37 \\
\hline Dış etkenler ile ilgili sorunlar & 1 & 1 & 2 & 3,12 \\
\hline Velilerin Illgisiz Olması & 1 & 0 & 1 & 1,56 \\
\hline Gezi yapılacak mekânların yetersiz olması & 0 & 1 & 1 & 1,56 \\
\hline
\end{tabular}

Tablo 5’te görüldüğü gibi sosyal bilgiler öğretmenlerinin tarihi kültürel miras eğitimi verirken \% 23,43 oranla en çok karşılaştıkları sorun okul yönetimi ile ilgili sorunlardır. Bunlar: \% 7,81'i gezi izinlerinin alınırken yaşanan problemler bir diğeri ise \% 15,62 materyal eksikliği konusunda yaşanan sorunlardır. Buna yakın bir başka sorun ise \% 18,75 ders ile ilgili sorunlardır. Bunlar: \% 3,12 kitapların yetersiz kalması, \% 6,25 sürenin yetersiz olması, \% 9,37 ise derste anlatımın soyut kalmasıdır. Diğer sorunlar ise \% 9,37 oranla öğrenci ile ilgili sorunlardır. Bunlardan en fazla \% 6,25 ile öğrencilerin ilgisiz olması, \%1,56'sı öğrencide anakronizm sorunu ve farklı kültürel mirasları benimsememe problemi olduğunu belirtmişlerdir. Bunların yanında \% 1,56'sı velilerin ilgisiz olmasını ve gezi yapılacak mekanların yetersiz olmasını içeren dış etkenler ile ilgili sorunların olduğunu belirtmişlerdir.

Ö1 kod isimli öğretmen tarihi kültürel miras eğitimi verilirken okullarda yeterli materyal olmaması sorunuyla karşılaştığını şu cümlelerle belirtmiştir:

"Tarihi kültürel miras eğitimi hakkında bir konu öğretilirken o konuda gerekli materyalin olması öğrencide kalıcı olmasını sağlayacaktır. Ancak okullarımızda yeterli materyal bulunmamaktadır."(Ö1).

Öğretmenlerden bazıları tarihi kültürel miras konusunun genişliğinden dolayı ders saati süresinin yetmediğini belirtmişlerdir:

"Tarihi kültürel miras eğitimi kapsamlı bir konudur ve bu konu anlatılırken süre yetersiz kalıyor."(Ö10).

"Sosyal bilgiler dersinin ders saati az olduğu için tarihi kültürel miras eğitimi konusunda etkinlik yapmaya zaman kalmıyor."(Ö15).

Ö17 kod isimli öğretmen tarihi kültürel miras eğitimi kapsamında yapılacak geziler için izin alma safhasında sorunlar yaşandığını şu şekilde belirtmiştir:

"Tarihi kültürel miras eğitimi konusu alan gezilerine müsait bir konu ancak okul dışı etkinlikler yapılırken ilgili makamlardan izin alma konusunda çok problemler yaşıyoruz."(Ö17).

Öğretmenlerden biri tarihi kültürel miras eğitimi verilirken öğrencilerin dönemin şartlarını dikkate almadan sorguladıklarını ve bu yüzden tarihi kültürel miras ögelerini benimsemediklerini şu şekilde açıklamıştır: 
“Öğrenciler tarihi kültürel miras eğitiminde işlenen tarihi mekânlar ya da adet, gelenek, göreneklerimizi dönemin şartlarıyla değil bugünün şartlarıyla yorumlayarak sorguluyorlar. Ayrıca başka dinlerden kalan eserleri benimsemiyorlar. Farklı kültürleri benimsemiyorlar."(Ö19).

Öğretmenlerin tarihi kültürel miras eğitimi konusu işlenirken karşılaştıkları sorunlar daha çok okul yönetimi, öğrenciler, araç gereç eksikliği, veliler ve gezi mekânlarının yetersizliğinden kaynaklı sorunlar olduğu söylenebilir.

Araştırmanın altıncı alt amacı olan “Öğretmenlere göre tarihi kültürel miras eğitimi hangi derslerde verilmelidir? Neden?” sorusuna ilişkin 13 temaya ulaşılmış, bu temalar Tablo 6’da verilmiştir.

Tablo 6. Öğretmenlerin Tarihi Kültürel Miras Eğitiminin Hangi Derslerde Verilmesi Gerektiği Konusundaki Görüşleri

\begin{tabular}{|c|c|c|c|c|}
\hline Temalar & Erkek & Kadın & $f$ & $\%$ \\
\hline Sosyal Bilgiler & 8 & 9 & 17 & 26,56 \\
\hline Din Kültürü ve Ahlak Bilgisi & 2 & 1 & 3 & 4,68 \\
\hline Teknoloji ve Tasarım & 3 & 3 & 6 & 9,37 \\
\hline Türkçe & 4 & 10 & 14 & 21,87 \\
\hline Müzik & 3 & 1 & 4 & 6,25 \\
\hline Beden Eğitimi & 2 & 0 & 2 & 3,12 \\
\hline Fen Bilgisi & 0 & 2 & 2 & 3,12 \\
\hline Matematik & 0 & 1 & 1 & 1,56 \\
\hline İngilizce & 0 & 1 & 1 & 1,56 \\
\hline Tarih & 1 & 2 & 3 & 4,68 \\
\hline Halk kültürü & 2 & 2 & 4 & 6,25 \\
\hline Diğer Seçmeli Dersler & 3 & 2 & 5 & 7,81 \\
\hline Sanat Tarihi & 2 & 0 & 2 & 3,12 \\
\hline
\end{tabular}

Tablo 6 'da sosyal bilgiler öğretmenlerinin tarihi kültürel miras eğitiminin hangi derslerde verilmesi gerektiği ile ilgili görüşlerine yer verilmiştir. Öğretmenlerin \% 26,56'sı sosyal bilgiler dersinde, \% 21,87'si Türkçe dersinde görülmesi gerektiği belirtilmiştir. Bununla beraber İngilizce ve matematik dersleri \% 1,56'sı tarafından tercih edilerek en az belirtilen dersler olmuştur. Araştırmaya katılan öğretmenlerden bazıları, tarihi kültürel miras eğitiminin diğer derslerde verilirken ne şekilde verilebileceğini şu şekilde açıklamışlardır:

"Sosyal bilgiler, din kültürü ve ahlak bilgisi ve teknoloji tasarım dersinde yer verilmelidir. Özellikle teknoloji ve tasarım dersinde tarihi kültürel miras ögelerimizle ilgili maket çalışmaları yapılabilir."(Ö1).

"Sosyal bilgiler dersinde ağırlıklı olması koşuluyla Türkçe dersinde metinler içerisinde tarihi kültürel miraslarımız işlenebilir."(Ö2).

"Sosyal bilgiler, din kültürü ve ahlak bilgisi, Türkçe derslerinin yanında fen bilgisi ve matematik gibi sayısal derslerde de bilim adamları, icatları ve buluşları konularıyla bağdaştırarak tarihi kültürel miras eğitimi konusu işlenmelidir."(Ö8).

Ö9 kod isimli öğretmen verilmesi gereken derslerin yanında bir öneri daha getirerek şu şekilde görüşünü belirtmiştir:

"Sosyal bilgiler, Türkçe vs. gibi kemik derslerde verilmesinin yanında üniversitede sosyal bilgiler öğretmenliğinde verilen sanat tarihi dersinin 5, 6 ve 7. sınıf düzeyine uygun şekilde müfredata eklenmesi gerekiyor."(Ö9).

Öğretmenlerden biri tarihi kültürel miras eğitiminin verilmesi gereken derslerin sınırlandırılmaması gerektiğini her derste verilebileceğini şu şekilde belirtmiştir:

"Sadece sosyal bilgiler dersinde verilmemeli, sınırlandırılmamalıdır. Diğer derslerin içinde verilmelidir. Hatta seçmeli bir ders olarak konulabilir. Ancak halk kültürü seçmeli dersi tamamen tarihi kültürel miras eğitimini yansıtmamasına rağmen seçmeli ders olduğu için öğretmenler ve öğrenciler tarafından yeterince önem verilmiyor."(Ö14).

Öğretmenlerin görüşlerine bakıldığında tarihi kültürel miras eğitimi konusunun her derse uyarlanabileceği görülmektedir.

Araştırmanın yedinci alt amacı olan “Öğretmenlere göre Denizli ilinin tarihi kültürel miras ögeleri nelerdir?” sorusuna ilişkin 21 temaya ulaşılmış, bu temalar Tablo 7'de verilmiştir.

Tablo 7. Öğretmenlerin Denizli İlindeki Tarihi Kültürel Miras Ögelerinin Neler Olduğu Konusundaki Görüşleri

\begin{tabular}{lcccc}
\hline Temalar & Erkek & Kadın & $f$ & $\%$ \\
\hline Akhan Kervansarayı & 3 & 2 & 5 & 7,69 \\
Germiyanlıŏulları Tarihi Vakıflar Hamamı & 1 & 0 & 1 & 1,53 \\
Kaklık Mağarası & 0 & 1 & 1 & 1,53 \\
Keloğlan Mağarası & 0 & 1 & 1,53 \\
Denizli Konağı & 0 & 1 & 1,53 \\
Buldan Tarihi Evleri & 4 & 2 & 6 \\
\hline
\end{tabular}

| Kastamonu Eğitim Dergisi, 2020, Vol. 28, No. 3| 


\begin{tabular}{|c|c|c|c|c|}
\hline Temalar & Erkek & Kadın & $f$ & $\%$ \\
\hline Hierapolis Antik Kenti & 5 & 6 & 11 & 16,92 \\
\hline Leodikya Antik Kenti & 4 & 5 & 9 & 13,84 \\
\hline Tarihi Öğretmenevi & 2 & 0 & 2 & 3,07 \\
\hline Denizli Lisesi & 2 & 0 & 2 & 3,07 \\
\hline Behice Sultan Höyüğü & 2 & 0 & 2 & 3,07 \\
\hline Atatürk Etnografya Müzesi Eserleri & 3 & 2 & 5 & 7,69 \\
\hline Buldan Kumaş ve Dokuması & 3 & 1 & 4 & 6,15 \\
\hline Zeybek Oyunu & 3 & 2 & 5 & 7,69 \\
\hline Çameli Budizm Kalıntıları & 1 & 0 & 1 & 1,53 \\
\hline Kaleiçi Tarihi Çarşısı & 1 & 0 & 1 & 1,53 \\
\hline Yöresel Yemekler & 3 & 3 & 6 & 9,23 \\
\hline Babadağlılar İşhanı & 0 & 1 & 1 & 1,53 \\
\hline Karahayıt kaplıcaları & 0 & 1 & 1 & 1,53 \\
\hline
\end{tabular}

Tablo 7'de sosyal bilgiler öğretmenlerinin Denizli ilindeki tarihi kültürel miras ögelerinin neler olduğu ile ilgili görüşlerine yer verilmiştir. En yüksek \% 16,92 oranla Hierapolis Antik Kenti söylenmiştir. İkinci sırada ise \% 13,84 Leodikya Antik Kenti gelmiştir. En düşük oranlar \% 1,53 ile Germiyanlığulları Tarihi Vakıflar Hamamı, Kaklık Mağarası, Keloğlan Mağarası, Denizli Konağı, Babadağlılar İşhanı, Karahayıt Kaplıcaları, Çameli Budizm Kalıntıları, Kaleiçi Tarihi Çarşısına verilmiştir. Denizli'nin tarihi kültürel miras ögeleri ile ilgili öğretmenlerin bazı görüşleri şunlardır:

"Denizli ili ilk çağlardan günümüze kadar pek çok devlete, insan topluluğuna mekân olmuş bir yöredir. Hierapolis antik kenti, Leodikya antik kenti, giyim tarzı, yemekleri, zeybek oyunu, mimari yapı özellikleri ve daha pek çok sayamadığımı kültür ögeleri ile zengin bir ilimizdir."(Ö2).

"Denizli tarih ve kültürünü incelerken şehir merkezi ve köyler diye ayrılmalıdır. Denizli'nin Acıpayam ve Teke yöresi kültürü ile Çal, Çivril taraflarındaki kültür arasında farklılıklar vardır. Örneğin, Çameli'nde Budizm'den kalan tarihi ögeler ve kültürel gelenekler vardır. Denizli savaşılmadan alınan ülkemizin ender yerlerinden biridir."(Ö17).

Öğretmen görüşlerine bakıldığında, Denizli ilinde yer alan tarihi kültürel miras eserlerinden haberdar oldukları söylenebilir.

\section{TARTIŞMA, SONUÇ VE ÖNERILER}

Yapılan bu araştırmada sosyal bilgiler öğretmenlerinin tarihi kültürel miras eğitimi hakkındaki görüşleri alınmıştır. Tarihi kültürel miras ögeleri bir toplum için, toplumun var olduğunun kanıtıdır. Tarihi kültürel miras ögelerini korumak ve yaşatmak için öncelikle onların neler olduğunu, neleri kapsadığı bilmek gerekir. Bu nedenle sosyal bilgiler öğretmenlerine tarihi kültürel miras ögelerinin neleri kapsadığı sorulmuştur. Öğretmenlerin çoğu, tarihi kültürel miras denilince akla ilk gelen ögenin geçmişten günümüze ulaşmış, geçmişe ışık tutan tarihi eserler olduğunu belirtmişlerdir. Sonrasında bu cevabı gelenek görenekler ve milli değerler takip etmiştir. Ünlü (2012)'nün araştırmasında ilköğretim öğrencilerinin kültür algıları incelenmiştir. Bunun sonucunda öğrencilerin kültürü geçmişle bağdaştırarak kültür ile ilgili farklı tanımlarda bulunduklarını belirtmiştir. Bunun yanında gelenek, göreneklerimiz, sözlü eserlerimiz, yazılı eserlerimiz, düğünlerimiz, sporlarımız, mimari yapıtlarımız, halk oyunlarımız ve bu temalar altında yer alan daha birçok ögelerimiz olduğu sonucuna varılmıştır. Deveci (2009), sosyal bilgiler öğretmen adaylarının hazırladığı kültür portfolyolarını incelemiştir. Sosyal bilgiler dersi ile kültür arasındaki ilişkiyi ortaya koymaya çalışmıştır. Araştırma sonucunda öğretmen adaylarının kendi kültürlerini anlatırken düğün, geçim kaynağı, halk oyunları, halk müziği ve ozanları, şive gibi çeşitli maddi ve manevi kültür ögelerinin yanında en çok yararlandıkları kültür ögesi yemek olmuştur.

Tarihi kültürel miras eğitimi konusunda örneklem grubu olarak sosyal bilgiler öğretmenlerinin seçilme nedeni bu konunun sosyal bilgiler programında ayrı bir öğrenme alanı olarak yer almasından ve sosyal bilgiler dersiyle doğrudan ve dolaylı olarak birçok bağlantısı bulunmasından dolayıdır. Bu nedenle tarihi kültürel miras eğitiminin sosyal bilgiler eğitimiyle olan ilişkisi sosyal bilgiler öğretmenlerinin görüşlerinden faydalanılarak ortaya çıkarılmak istenmiştir. Sosyal bilgiler dersiyle tarihi kültürel miras eğitimi dersinin ilişkili olduğunu gösteren bazı araştırmalar bulunmaktadır. Deveci (2009)'nin yapmış olduğu araştırmada sosyal bilgiler öğretmenlerinin görüşlerinden çıkan sonuçları pekiştirir niteliktedir. Yapılmış olan araştırmada öğretmen adaylarının tamamı kültür ile sosyal bilgiler arasında yakın bir ilişki olmasının sebebi olarak, sosyal bilgilerin bir insan bilimi olması ve disiplinler arası yaklaşımla ele alınmasını göstermişlerdir. Bununla birlikte sosyal bilgiler dersinde bireyin kendini, yakın çevresini, başka toplumları sosyal bilgiler dersi ile öğrendiği bu nedenle sosyal bilgiler dersinde kültür öğretimi yapıldığı belirtilmiştir.

Tarihi kültürel miras eğitiminin sosyal bilgiler programında yeterince yer verilip verilmediği ile ilgili yapılan görüşmede öğretmenlerin çoğu detaylı bir şekilde anlatılmadığını belirtmiş ve ders kitaplarında yapılandırmacı eğitim gereği bilgi yoğunluğunun azaltılması nedeniyle kültürel miraslar konusunda da yeterli bilgiye ulaşılamamasının başka bir sorun olduğunu belirtmişlerdir. İlgili konuya dair bilgilere ulaşmak için ekstra yardımcı kitap önermenin yasak olması öğretmenlerin en çok yakındıkları sorunlardan biri olmuştur. Bu görüşlerin aksine yapılan araştırmaların bazılarında ise sosyal bilgiler programında bu konulara yeterince yer verildiği sonuçlarına ulaşılmıştır. Örneğin, Çengelci (2012)'nin yapmış olduğu araştırmada sosyal bilgiler öğretim programında somut olmayan kültürel mirasın yeri araştırılmış ve somut olmayan kültürel miras ögelerinin 7. sınıf sosyal 
bilgiler öğretim programında yer aldığı gözlemlenmiş. Bunun yanında kazanım ve etkinlik örneklerinin en fazla kültür ve miras öğrenme alanı içerisinde yer aldığını ifade edilmiştir. Bıyıklı (2010), sosyal bilgiler ders kitaplarında kültürel miras konusunun ve kültürel miras ögelerinin nasıl sunulduğu konusunda bir araştırma yapmıştır. Bu araştırmada kültürel miras ögelerine geçmişten bu yana önem verildiği ve bu nedenle kültürel mirasla ilgili görsellerin geçmişten günümüze sosyal bilgiler ders kitaplarında önemli ölçüde yer aldığı belirtilmektedir. Aslan ve Çulha (2008)'nın yapmış olduğu araştırmada da Türkiye'deki 4. ve 6 . sınıf öğrencileri üzerinde yaptıkları araştırmaya göre, öğretim programında kültürel miras eğitiminin ulusal kimlik geliştirilmesinde başarılı olduğu sonucuna varılmıştır.

Tarihi kültürel miras eğitiminin öğrencide merak uyandırması ve kalıcı olması için bazı yöntem tekniklerle desteklenmelidir. Araştırma sonucunda bu yöntem ve teknikler sınıf içi ve sınıf dışı olarak analiz edilmiştir. Araştırmaya göre öğretmenlerin çoğu gözlem tekniğini tercih etmişlerdir. Bu konu ile ilgili Dönmez ve Yeşilbursa (2014)'nın araştırması bunu destekler niteliktedir. Araştırmada altıncı sınıf öğrencilerine sosyal bilgiler dersi kapsamında somut kültürel miras ögeleri ile ilgili öğrencilerin aktif olarak sürecin içinde yer aldığı etkinliklerden oluşan bir kültürel miras eğitimi verilmiştir. Araştırma sonucunda öğrencilerin somut kültürel mirasa karşı olumlu tutum geliştirmelerinde etkili olmuştur. Bazılarına göre ise gezi gözlem tekniği için uygun ortam ve imkân olmaması durumunda drama ve sanal müze ile öğretimin yapılması gerektiği görüşünü belirtmişlerdir. Aynı şekilde müze gezisi yapılarak da o dönemlere ait eserleri görme imkânı olacağını ve müzelerde etkinlikler yapılarak bu eserlerin tanıtılabileceğini belirten öğretmenler de bulunmaktadır. Bu konuyla ilgili Ulusoy (2009)'un ilköğretim 4. ve 5. sınıf öğrencilerinin kültür ve miras öğrenme alanının işlenişi ile ilgili görüşlerinin değerlendirilmesine yönelik yaptığı araştırmasında, kültür ve mirasları yansıtan çeşitli görsel unsurlardan faydalanılarak etkinlikler yaptırılması gerektiği şeklinde belirtilmiştir.

Tarihi kültürel miras eğitimine ilişkin öğretmenlerin karşılaştıkları sorunlar bulunmaktadır. Görüşmeler sonucunda öğretmenlerin yaklaşık yarısı materyal eksikliği ile ilgili sorunlarla karşılaştıklarını belirtmişlerdir. Bunun yanında tarihi kültürel miras ögeleri ile ilgili yapılan maket, afiş vs. görsel materyal ürünlerini saklamak için okullarda yeterli alan bulunmadığı ve bu nedenle dersle ilgili materyale ulaşmanın sorun olduğunu belirtmişlerdir. Öğretmenlerin bazıları anlatımın teorik olduğu ve bu nedenle soyut kaldığı yönünde olmuştur. Sorunlardan bir başkası da izin için prosedürlerin çok olmasından dolayı öğretmenlerin müze ve ören yeri türü tarihi kültürel miras ögeleri ile zengin alanlara yapılan gezileri fazla tercih etmemesidir.

Tarihi kültürel miras eğitiminin verilebileceği dersler konusunda öğretmenlerin çoğu sosyal bilgiler dersinde verilmesi gerektiğini ancak sadece bir derse sıkıştırılmak yerine diğer derslerde de verilebileceği yönünde görüşler sunmuşlardır. Türkçe dersini de bu konu da uygun olduğunu savunan öğretmenlerde bulunmaktadır. Öğretmenler Türkçe dersinde bu ögelerin okuma metinlerinde yer verilebileceğini belirtmişlerdir. Bazı öğretmenler de teknoloji ve tasarım dersinde gerek resim çizimlerinde gerekse maket hazırlamalarında tarihi kültürel miras ile ilgili konularla etkinlikler yapılabileceğini belirtmişlerdir.

Tarihi kültürel miras ögelerinin neleri kapsadığı yönünde olan soruya benzer bir soru olan Denizli ilinin tarihi kültürel miras ögelerinin neler olduğu konusunda öğretmenler sırasıyla Hierapolis Antik Kenti, Leodikya Antik Kenti, Buldan Tarihi Evleri, yöresel yemekler, zeybek oyunu, Atatürk Etnografya Müzesi ve Eserleri şeklinde görüşlerini belirtmişlerdir.

Sonuç olarak, tarihi kültürel miras ögelerinin, tarihi eserler, mimari yapıtlar, milli değerler, gelenek ve görenekler sözlü eserler, halk oyunları, düğünler ve yazılı eserleri kapsadığı ortaya konulmuştur. Ayrıca tarihi kültürel miras eğitiminin sosyal bilgiler dersiyle ilişkisi üç tema altında toplanmıştır. Bunlar, sosyal bilgiler dersinin toplumla ilişkisi nedeniyle tarihi kültürel miras ögelerinin de toplum olarak hayatımızın önemli bir yerinde bulunmasından dolayı bağlantılı olduğunu belirtmişlerdir. İkinci olarak, sosyal bilgiler dersinin disiplinlerarası bir ders olduğu ve bu yüzden tarihi kültürel miras eğitimi konusunun sosyal bilgiler eğitiminde yer alması gerektiği yönünde öğretmenlerin görüşleri yer almıştır. Üçüncüsü ise, tarihi kültürel miras eğitiminin sosyal bilgiler dersinin amaçları içerisinde yer almasından dolayı ilişkili olduğunu belirtmişlerdir. Sosyal bilgiler dersi öğretim programında da tarihi kültürel miras eğitimine yeterince yer verildiği görülmüştür. Sosyal bilgiler dersinde tarihi kültürel miras eğitiminin soru cevap, sunuş yöntemi, beyin fırtınası, münazara, drama, sanal müze ve görsel materyal kullanımını içeren sınıf içi etkinliklerle yapılması uygun görülmüştür. Tarihi kültürel miras eğitimi verilirken okul yönetimi, öğrenci, ders dış etkenler ile ilgili sorunlarla karşılaşıldığı belirtilmiştir. Tarihi kültürel miras eğitimi sosyal bilgiler dersinin yanında din kültürü ve ahlak bilgisi, teknoloji ve tasarım, Türkçe, müzik, beden eğitimi, fen bilgisi, matematik, İngilizce, tarih, halk kültürü, diğer seçmeli dersler, sanat tarihi derslerinde verildiği belirtilmiştir. Denizli ilindeki tarihi kültürel miras ögelerinin neler olduğu ile ilgili Hierapolis Antik Kenti, Leodikya Antik Kenti, Germiyanlığulları Tarihi Vakıflar Hamamı, Kaklık Mağarası, Keloğlan Mağarası, Denizli Konağı, Babadağıılar İşhanı, Karahayıt Kaplıcaları, Çameli Budizm Kalıntıları, Kaleiçi Tarihi Çarşısı olduğu belirtilmiştir.

Araştırmaya katılan sosyal bilgiler öğretmenlerinin görüşlerinden yola çıkarak birkaç öneride bulunulabilir. Bunlar:

- Sosyal bilgiler öğretiminde tarihi kültürel miras konularının teorik olarak kalmasından ziyade görseller ve etkinliklerle zenginleştirilerek, daha fazla yer verilmelidir.

- 5. sınıfta tarihi kültürel miras eğitimine yoğun şekilde yer verilmesinin öğrencinin yaş seviyesine uygun olmadığını düşünen öğretmenlerden bazıları tarihi kültürel miras eğitimine 6 ve 7. sınıf düzeylerinde yoğunluk verilmesini önermişlerdir. Bu nedenle 5. sınıfta giriş düzeyinde tarihi kültürel miras eğitimi verilirken 6 ve 7. sınıfta pekiştirme ve geliştirme düzeyinde eğitim verilerek çocuğun seviyesine uygun hale getirilebilir.

- Müze ve ören yeri gibi tarihi kültürel miras ögeleri yönünden zengin olan alanlara planlanan gezilerin il/ilçe belediyeleri ya da Gençlik ve Spor Bakanlığı tarafından yapılması hem maddi olanaklar açısından hem de izin alma konusundaki sıkıntılardan dolayı iyi bir seçenek olabilir. Bu geziler yapılırken öğrencilere bu alanlarla ilgili olan önemli

| Kastamonu Eğitim Dergisi, 2020, Vol. 28, No. 3| 
olayların ve korunması gerektiğiyle ilgili bilgilerin yer aldığı bir afiş dağıtılması gezide daha aktif olmalarını sağlayabilir. Aynı zamanda bu tür tarihi kültürel miras alanlarında drama türü etkinlikler yapılarak öğrenilen bilgilerin kalıcılığını arttırmanın yanında öğrencinin sıkılmaması da sağlanabilir.

\section{KAYNAKÇA}

Akay, A.S. (2006). Somut olmayan kültürel mirasın tarih araştırmalarında kaynak olma özelliği. Milli Folklor Dergisi, 70.

Aksoy A. ve Enlil Z. (2012). Kültürel miras yönetiminde çağdaş yaklaşımlar. A. Aksoy ve D. Ünsal (Ed.), Kültürel miras yönetimi içinde (1. baskı, ss. 2-28). Eskişehir: Anadolu Üniversitesi Yayınları.

Arıkan, İ. (2012). İlköğretim 7. sınıf öğrencilerinin kültürel miras ile ilgili başarı düzeyleri ve tutumlarının bazı değişkenlerle incelenmesi: Adıyaman örneği. Yayımlanmamış yüksek lisans tezi. Adıyaman Üniversitesi, Adıyaman.

Aslan, E. ve Çulha B. (2008). “Kimiz biz" Türkiye'deki ilköğretim okullarında “ulusal kimlik" ve "kültürel miras eğitimi”. M. Safran ve D. Dilek (Ed.), 21. yüzyılda kimlik, vatandaşlık ve tarih eğitimi içinde (ss. 131-133). İstanbul: Yeni İnsan Yayınevi.

Aslan, Z., Ardemagni, M. (2006). Introducing young people to the protection of heritage sites and historic sites. http://www.iccrom.org/ifrcdn/pdf/ICCROM_09_ManualSchoolTeachers_en.p df. adresinden alındı.

Artun, E. (2005). Popüler Türk kültürünün dünya kültürlerine etki ve katkısı. http://turkoloji.cu.edu.tr/HALKBILIM/50.php adresinden alındı.

Avcı, M. ve Memişoğlu, H. (2016). Kültürel miras eğitimine ilişkin sosyal bilgiler öğretmenlerinin görüşleri. illköğretim Online, 15(1),104-124.

Başar, E. (1994). Eğitim sosyolojisi. Samsun: Eser Matbaası.

Bıyıklı, S. G. (2010). Representation of cultural heritage in textbooks: Examination of the illustration in the 4th and 5th grade social studies textbooks (1974-2009) in Turkey. Yayımlanmamış yüksek lisans tezi. Koç Üniversitesi, İstanbul.

Büyüköztürk, Ş., Çakmak, K. E., Akgün, E. Ö., Karadeniz, Ş. ve Demirel, F. (2011). Bilimsel araştırma yöntemleri. Ankara: Pegem Akademi Yayıncılık.

Çankaya, E. (2006). Somut olmayan kültürel mirasın müzecilik bağlamında korunması. Yayımlanmamış yüksek lisans tezi. Yıldız Teknik Üniversitesi, İstanbul.

Çengelci, T. (2012). Sosyal bilgiler öğretim programında somut olmayan kültürel mirasın yeri. Uludağ Üniversitesi Eğitim Fakültesi Dergisi, 25(1), 185-203.

Çulha, B. (2006-2007). Uluslarası mevzuatlar ışığında Türk eğitim sisteminde kültürel miras ve koruma: Genel değerlendirmeler ve öneriler. http://www.kumid.net/euproject/uzmanlar_raporu.html adresinden alındı.

Çulha Özbaş, B. (2014). Illköğretim sosyal bilgiler derslerinde kültürel miras eğitimi. M. Safran (Ed.), Sosyal bilgiler eğitimi içinde (ss. 743-762). Ankara: Pegem Akademi.

Deveci, H. (2009). Sosyal bilgiler dersinde kültürden yararlanma: öğretmen adaylarının kültür portfolyolarının incelenmesi. Elektronik Sosyal Bilimler Dergisi, 8 (28), 1- 19.

Deveci, H. ve Selanik Ay, T. (2011). Sosyal bilgiler dersinde yerel toplum çalışmalarından yararlanma: bir eylem araştırması. Journal of Social Studies Education Research, 2(1), 83-115.

Dönmez, C. ve Yeşilbursa, C.C. (2014). Kültürel miras eğitiminin öğrencilerin somut kültürel mirasa yönelik tutumlarına etkisi. İlköğretim Online, 13 (2), 425-442.

Durant, W. (1978). Medeniyetin temelleri (N. Muallimoğlu, Çev.). İstanbul: Erguvan yayınları.

Gökkaya, A.K. ve Yeşilbursa, C.C. (2009). Sosyal bilgiler öğretiminde tarihi yerlerin kullanımının akademik başarıya etkisi. Türk Eğitim Bilimleri Dergisi. 7(2), 483- 506.

Günay, Ü. (2005). Din Sosyolojisi. İstanbul: İnsan Yayınları.

Harper, M. (1997). Including historic places in the social studies curriculum. http://www.ericdigests.org/1998-2/places.htm adresinden alındı.

MEB, (2005). illköğretim sosyal bilgiler öğretim programı ve kılavuzu (6-7.sınıflar). Ankara: Talim ve Terbiye Kurulu Başkanlığı.

Miles, M. B. \& Huberman A. M. (1994). Qualitative data analysis: an expanded sourcebook. Thousand Oaks. CA: Sage.

Öcal, T. (Haziran, 2014). Somut olmayan kültürel miraslarımızdan halıcılığın Niğde'de yaşatılıp sürdürebilirliği. Coğrafyacılar Derneği Uluslararası Kongresi Bildiri Kitabı, Muğla Sıtkı Koçman Üniversitesi, Muğla.

Özbaş, B. (2012). Illköğretim sosyal bilgiler derslerinde kültürel miras eğitimi. M. Safran (Ed.), Sosyal bilgiler öğretimi içinde (ss. 746 -752). Ankara: Pegem Akademi.

Prott, L.V. \& Patrick, J.O. (1992). Cultural heritage or cultural property? https://doi.org/10.1017/S094073919200033X adresinden alındı.

Sertkaya, K. B. (2010). İlköğretim ikinci kademe sosyal bilgiler dersi öğretiminde kültür aktarımı ve kültürel kimlik geliştirme. Yayımlanmamış yüksek lisans tezi. Balıkesir Üniversitesi, Balıkesir.

Sidekli, S. ve Karaca, L. ( 2013). Sosyal bilgiler öğretiminde yerel, kültürel miras ögelerinin kullanımına ilişkin öğretmen adayı görüşleri. Gaziosmanpaşa Bilimsel Araştırma Dergisi, 5, 20-38.

Smith, G.S., Messenger, P.M. \& Soderland, H.A. (2010). Heritage values in contemporary society. Walnut Creek, California: Left Coast Pess İnc.

Sokal, M.P. (2006). The U.S. legal response to the protection of the world cultural heritage. N. Bro die, M. M. Kersel, C. Luke, K. W. \& Tubb (Ed.), Archaeology, cultural heritage, and the antiquities trade içinde (ss. 36-67). Gainesville, FL: University Press of Florida.

Sözen, S. (2013). A phenomenological study on incorporating the history of mathematics into teaching from the perspective of primary and mathematics teachers. Yayımlanmamış yüksek lisans tezi. Orta Doğu Teknik Üniversitesi, Ankara. 
Sözer, E. (1998). Sosyal bilimler kapsamında sosyal bilgilerin yeri ve önemi. G. Can (Ed.), Sosyal bilgiler öğretimi içinde (ss. 1-13). Eskişehir: Anadolu Üniversitesi Açıköğretim Fakültesi Yayınları.

Ulusoy, K. (2009). Sosyal Bilgiler dersi kültür ve miras öğrenme alanının işlenişinin 4. ve 5. sınıf öğrencileri tarafından değerlendirilmesi. Akademik Bakış Uluslararası Hakemli Sosyal Bilimler e-Dergisi, 18, 1-26.

Ünlü, ì. (2012). İlköğretim 8. sınıf öğrencilerinin kültür algılarının incelenmesi. Ahi Evran Üniversitesi Kırşehir Eğitim Fakültesi Dergisi, 13(1), 7792.

Yalçınkaya, E. (2015). Pre-service teachers' views on intangible cultural heritage and its protection. Anthropologist, 22(1), 64-72.

Yeşilbursa, C.C. (2008). Sosyal bilgiler öğretiminde tarihi yerlerin kullanımı. Türklük Bilimi Araştırmaları Dergisi, 23(23), $209-222$.

Yeşilbursa, C.C. ve Barton, K.C. (2011). Preservice teachers' attitudes toward the inclusion of "heritage education" in elementary social studies. Journal of Social Studies Education Research. 2(2), 1-21.

Yeşilbursa, C.C. ve Uslu, S. (2014). Türk ve Amerikan sosyal bilgiler öğretmen adaylarının kültürel miras eğitimine yönelik tutumlarının karşılaştırılması. Turkish Studies International Periodical for the Languages, Literature and History of Turkish or Turkic, 9(8), 879-891.

Yıldırım, A. ve Şimşek H. (2013). Sosyal bilimlerde nitel araştırma yöntemleri. Ankara: Seçkin Yayıncılık. 